\title{
A Difference that Makes a Difference: Welfare and the Equality of Consideration
}

\author{
Elijah Weber \\ Philosophy Department \\ Bowling Green State University \\ eliweber1980@gmail.com
}

\begin{abstract}
In Welfare, Happiness, and Ethics, L.W. Sumner defends two significant constraints on one's theory of welfare: formality and generality. An adequate theory of welfare, claims Sumner, must give a constitutive account of the "good-for" relation. This constitutive account must be sufficiently general that any entity whose status as a welfare subject is uncontroversial falls within its scope. This paper will argue that Sumner's proposed constraints are particularly significant to utilitarian arguments for the equal moral considerability of non-human animals. In the absence of these constraints, the inconsistency that is alleged to follow from denying moral considerability to non-human animals, while affirming it for humans, fails to obtain. I will focus on Peter Singer's argument for the equal moral considerability of non-human animals, in order to support the conclusion that questions about the formality and generality of welfare are significant areas of further research for philosophers of animal welfare.
\end{abstract}

\section{Introduction: Welfare and Animal Ethics}

Welfare is about how well an individual is faring, relative to the circumstances of their life. Well-being and prudential value are both synonymous with welfare, such that talk about an individual's wellbeing, or the prudential value of some aspect of their lives, is taken to be about their welfare. There are many different accounts of what welfare is, but all largely agree that welfare concerns how individuals are faring, and that welfare matters for ethics. Thus, questions about animal welfare are properly questions about how non-human animals are faring, and what sorts of things would make their lives better for them.

In Welfare, Happiness, and Ethics, L.W. Sumner proposes two requirements for an adequate theory of welfare. One of these is the requirement of generality. This requirement states that an adequate theory of welfare should accommodate the wide variety of types of welfare subjects to which our welfare vocabulary is applied (Sumner 
1996, 14). This is a controversial suggestion, since we speak similarly about the well-being of other humans, non-human mammals, mollusks, houseplants, and even automobiles. Sumner claims that this controversy can be addressed by distinguishing between the core welfare subjects and the periphery. Whereas there is bound to be disagreement about whether fringe entities are truly welfare subjects, an adequate theory of welfare would have to at least account for beings about which there is no such disagreement (Sumner 1996, 15).

Another requirement proposed by Sumner is the requirement of formality. Sumner's proposal here is that a theory of welfare must do more than simply offer a list of the sources of welfare. Rather, a theory of welfare must provide a constitutive account of the good-for relation (Sumner 1996, 17). While adequate food, access to clean water, affordable medical care, and a decent education might all be important for a person's well-being, this doesn't explain why all of these things belong on this list. A theory of welfare must explain what is common to the variety of sources of welfare, even across species lines, which qualify them as sources of welfare. Sumner notes that this amounts to a "unitary theory of welfare," whereby the goodfor relation is taken to hold across relata (Sumner 1996, 17). In what follows, I will also refer to Sumner's formality requirement by reference to the notion that welfare is unitary.

The formality and generality of welfare are proposed by Sumner as constraints that are intended to guide inquiry into the nature of welfare, but these requirements have also played a prominent role in utilitarian arguments for the equal moral considerability of non-human animals. Peter Singer, Bernard Rollin, and R.G. Frey are among the proponents of such arguments (Singer 1975, Rollin 2006, Frey 1983). Though Rollin and Frey disagree with Singer on a number of key points, they all agree that there is a fundamental inconsistency in denying moral considerability to nonhuman animals while granting it to human beings. Their arguments have been successful because they highlight something that seems obvious, but is often taken for granted in our daily lives. If humans 
fare better to the extent that their pain is minimized and their pleasure is maximized, why think non-human animals are any different? Perhaps the most successful of these types of arguments is Peter Singer's argument that denying equal moral considerability to non-human animals is a form of prejudice that he dubs "speciesism" (Singer 1975). Singer's argument contends that it is the capacity for suffering which is the sufficient condition for having interests, and that all beings that have interests are due equal moral consideration (Singer 1975, 2-9). Since non-human animals have the capacity for suffering, non-human animals are therefore due the same moral consideration that humans receive. It is only in virtue of species-specific prejudice that humans neglect to extend due moral consideration to non-human animals. Singer rightly concludes that speciesism, like racism and sexism, are unjustifiable forms of discrimination.

Singer's argument, though compelling, rests on two assumptions that reflect Sumner's constraints: that welfare is a unitary concept and that a theory of welfare must be general. Singer's argument assumes that welfare amounts to the same thing for humans and non -human animals. This paper will first explain the role that these two assumptions play in Singer's argument, and then demonstrate that the inconsistency that is alleged to follow from denying the moral considerability of non-human animals is avoidable if one either rejects the generality requirement or denies that welfare is unitary. Both of Sumner's requirements may be appropriate constraints on a theory of welfare, but in the absence of convincing arguments to this effect, they are nothing more than undefended assumptions that are crucial to the success of utilitarian arguments for the equal moral considerability of non-human animals. These considerations thus represent an important area for further philosophical research on welfare in general, and animal welfare in particular.

\section{Welfare and the Moral Considerability of Humans}

In Animal Liberation, Peter Singer offers a utilitarian argument for the equal moral considerability of non-human animals 
(Singer 1975, 2-9). It is important to specify the sense in which this argument is a utilitarian one. After all, Singer is not here advocating that the morally best action is the one which leads to the greatest aggregate amount of happiness (though Singer sometimes speaks this way about both human and animal welfare). Rather, Singer's argument for the moral considerability of non-human animals emphasizes the utilitarian commitment to the unique moral significance of welfare (Sumner 1996, 186). Singer's argument, though he utilizes the language of pleasures, pains, and interests, is properly an argument from the moral significance of welfare. The form of Singer's argument from Animal Liberation, as applied to the human case, is the following:

1. If humans can experience pleasure and pain, then humans have interests.

2. Humans can experience pleasure and pain.

3. Therefore, humans have interests.

4. If humans have interests, then humans are due moral consideration.

5. Therefore, humans are due moral consideration(Singer 1975, 5-8).

Singer concludes that it would be inconsistent to accept this argument but reject the same argument concerning non-human animals. But before we assess this claim, let's consider whether this argument is sound as it stands.

The above formulation of Singer's argument suggests that being able to experience pleasure and pain is a sufficient condition for having interests, and that having interests is sufficient for moral considerability. But why think the fourth premise, that having interests is sufficient for being morally considerable, is true? Depending on how we formulate the notion of having an interest, entities that are not obviously morally considerably might qualify as having interests. For example, if organisms have an interest in whatever keeps them alive, then plants have interests. Corporations 
clearly have interests, but they are not obviously due equal moral consideration in virtue of this.

The first premise might be thought to eliminate this possibility, since plants and corporations lack the capacity for pleasure and pain. But the first premise is a conditional statement establishing pleasure and pain as a sufficient condition for having interests. It is perfectly consistent to accept the first premise while rejecting the fourth, on the grounds that while the capacity for pleasure and pain is sufficient for having interests, having interests is not sufficient for moral considerability. The worry here is simply that we need some reason to think that having interests is sufficient for being morally considerable, both generally and because some entities that have interests do not seem to be morally considerable.

This concern can be avoided by revealing an implicit premise which connects having interests to being a welfare subject, and then inferring moral considerability from the fact that one is a welfare subject. Such a strategy is consistent with the utilitarian commitment to welfare as the sole source of intrinsic value. The modified version of Singer's argument is as follows:

1a. If humans can experience pleasure and pain, then humans have interests.

2a. Humans can experience pleasure and pain.

3a. Therefore, humans have interests.

4a. If humans have interests, then humans are welfare subjects.

5a. Therefore, humans are welfare subjects.

6a. If humans are welfare subjects, then humans are due moral consideration.

7a. Therefore humans are due moral consideration.

This argument commits Singer to the satisfaction of interests as a constituent of the good-for, since it makes having interests sufficient for being a welfare subject. However, it does not commit him to an 
interest-satisfaction theory of welfare, wherein the good-for relation is specified solely in terms of the satisfaction of a subject's interests. In the next section, I will argue that Singer's commitment to the claim that it would be inconsistent to affirm the moral considerability of human beings while denying equal moral consideration to nonhuman animals does commit him to a unitary theory of welfare, where interest-satisfaction is a constituent of the good-for relation for both humans and non-human animals.

\section{Inferring the Moral Considerability of Non-Human Animals}

So far, I have argued that in order to infer the moral considerability of humans from the fact that they have interests, Singer must appeal to interest-satisfaction as a constituent of welfare. Next, I will present Singer's argument for the moral considerability of non-human animals and demonstrate the role of the formality and generality of welfare in arguments of this sort. Below is Singer's argument for the moral considerability of non-human animals, along with my proposed amendment revealing Singer's implicit premise.

1b. If non-human animals can experience pleasure and pain, then non-human animals have interests.

2b. Non-human animals can experience pleasure and pain.

3b. Therefore, non-human animals have interests.

4b. If non-human animals have interests, then non-human animals are welfare subjects.

5b. Therefore, non-human animals are welfare subjects.

6b. If non-human animals are welfare subjects, then non-human animals are due moral consideration.

7b. Therefore, non-human animals are due moral consideration.

As in the human case, moral considerability follows from being a welfare subject, rather than simply having interests or being capable of pleasure and pain. And like the argument for the moral considerability of humans, this argument also depends on interest- 
satisfaction being constitutive of the good-for relation, whether partially or completely. It is tempting to think that interests need only be partially constitutive of the good-for relation for Singer's argument to be sound in both cases, and that the additional constituents of welfare can differ according to subject type. By considering the general form of Singer's argument, it becomes clear why this is not the case.

1c. If $X$ can experience pleasure and pain, then $X$ has interests. 2c. X can experience pleasure and pain.

3c. Therefore, $\mathrm{X}$ has interests.

4c. If $X$ has interests, then $X$ is a welfare subject.

$5 \mathrm{c}$. Therefore, $\mathrm{X}$ is a welfare subject.

6c. If $\mathrm{X}$ is a welfare subject, then $\mathrm{X}$ is due moral consideration.

7c. Therefore, $\mathrm{X}$ is due moral consideration.

For this to be a valid argument, being a welfare subject must mean the same thing whatever object is substituted for X. As I discussed in the first section of this paper, being a welfare subject involves being the sort of creature for whom things can go better or worse. If the way in which things go better or worse for a human being is constitutively different from the way that things go better or worse for non-human animals, then being a welfare subject does not mean the same thing for both humans and non-human animals. Thus, for the general form of Singer's argument to be valid, welfare must be a unitary concept. The good-for relation must be constitutively identical, otherwise Singer's argument equivocates on the term "welfare." Either the good-for relation must be specified solely in terms of interest-satisfaction, or the additional constituents of the good-for relation must be the same for humans and non-human animals.

This is not a problem for Singer's argument, but it is a necessary concession for the form of his argument to be valid. If Singer defends 
a single account of the good-for relation that includes interestsatisfaction as a constituent, then both humans and non-human animals qualify as welfare subjects in virtue of having interests, because "welfare" refers to the same thing throughout Singer's argument. To deny the moral considerability of non-human animals while affirming it for humans then would be inconsistent, because non-human animals clearly meet the sufficient condition for being welfare subjects, and therefore qualify for moral consideration. A unitary theory of welfare does commit one to the conclusion that non -human animals are due equal moral consideration, as Singer claims. That this is a desirable outcome for one's theory of welfare is supported by Sumner's generality requirement, which says that an adequate theory of welfare must capture the core class of welfare subjects within its scope.

\section{Avoiding Inconsistency: Two Strategies}

Despite the seemingly positive resolution of some initial concerns with Singer's argument, there is reason to think that his argument remains susceptible to serious challenges. In this section, I will offer two strategies for avoiding the inconsistency charge that makes Singer's argument so effective. The goal of this section is to demonstrate that both the generality and formality requirements proposed by Sumner are necessary for Singer's inconsistency charges to stick. In the absence of either requirement, one can easily explain why there is no inconsistency in accepting the moral considerability of human beings while failing to grant equal moral consideration to non-human animals.

\section{Solution \#1: Reject the Generality Requirement}

Suppose one were to accept the unity of welfare, but deny the generality requirement, as well as denying that welfare is even partially constituted by interest satisfaction. One might instead hold, for example, that welfare is constituted by the satisfaction of a subject's desires (Sumner 1996, 113-137). This allows one to accept Singer's argument in the human case, but reject it in the animal case. 
To illustrate this, let's examine both arguments, along with the truthvalue assignments that would reflect this position.

1d. If humans have desires that can be satisfied, humans are welfare subjects. - T

2d. Humans have desires that can be satisfied. - T

3d. Therefore, humans are welfare subjects. - T

4d. If humans are welfare subjects, then humans are due moral consideration. - $\mathrm{T}$

5d. Therefore, humans are due moral consideration. - $\mathrm{T}$

1b. If non-human animals can experience pleasure and pain, then non-human animals have interests. - $\mathrm{T}$

2b. Non-human animals can experience pleasure and pain. - $\mathrm{T}$

3b. Therefore, non-human animals have interests. - T

4b. If non-human animals have interests, then non-human animals are welfare subjects. - F

5b. Therefore, non-human animals are welfare subjects. - F

6b. If non-human animals are welfare subjects, then non-human animals are due moral consideration. - $\mathrm{T}$

7b. Therefore, non-human animals are due moral consideration. - F

This position does not involve the implausible claim that non-human animals can't feel pleasure and pain. Nor does it reject the conditional in premise $6 \mathrm{~b}$, which affirms that being a welfare subject is the relevant characteristic for moral considerability. But it does allow one to reject the inconsistency charge. If the satisfaction of our desires is sufficient for being a welfare subject, as stated in premise $1 \mathrm{~d}$, and the good-for relation is a single relation that holds across relata, as the formality requirement maintains, then the fact that non -human animals have interests is not directly relevant to whether they have a welfare, because interest satisfaction is not a constituent of welfare on this view. And if one rejects the generality requirement, 
which says that an adequate theory of welfare should reflect the scope of our welfare language, then the fact that non-human animals turn out not to be welfare subjects on this view is not a deficiency for one's theory of welfare. Rejecting generality, while affirming that welfare is unitary, allows one to defend a single constitutive account of welfare that is not applicable to non-human animals. This might be an implausible view of welfare, but implausibility is not inconsistency. A desire-satisfaction theory of welfare, where welfare is unitary but not general, allows one to consistently affirm the moral considerability of humans while denying equal moral consideration to non-human animals.

\section{Solution \#2: Deny that Welfare is a Unitary Concept}

Avoiding Singer's inconsistency charge by adopting a unitary, desire-satisfaction theory of welfare while rejecting the generality requirement, though effective, might seem somewhat disingenuous. After all, Singer's point is properly that if one accepts that having interests is sufficient for being a welfare subject, thereby granting moral considerability to any being with interests, it would then be inconsistent not to grant moral considerability to non-human animals. The first proposed solution relies heavily on the rejection interest-satifaction as a constituent of welfare. But suppose one were to accept that interest-satisfaction is a constituent of welfare in the human case. Also, suppose one were to affirm the generality requirement, maintaining that a theory of welfare must reflect our ordinary welfare talk and capture the core class of welfare subjects within its scope. Finally, suppose that one denies the unity of welfare. This opens up the possibility of multiple, distinct accounts of welfare, where the constituents of welfare are not the same.

This position might seem immediately attractive, since it recognizes that an adequate theory of welfare minimally ought to reflect the least controversial ways that we use welfare language while allowing that the constituents of welfare might be dependent on the type of welfare subject. This view also captures the common sense proposal that human well-being is importantly connected to interest- 
satisfaction. However, it doesn't establish the inconsistency that Singer's argument is dependent on. This is demonstrated by the two arguments below.

1a. If humans can experience pleasure and pain, then humans have interests. - $\mathrm{T}$

2a. Humans can experience pleasure and pain. - $\mathrm{T}$

3a. Therefore, humans have interests. - T

4a. If humans have interests, then humans are welfare subjects. - T

5a. Therefore, humans are welfare subjects. - T

6a. If humans are welfare subjects, then humans are due moral consideration. - $\mathrm{T}$

7a. Therefore humans are due moral consideration. - T

1b. If non-human animals can experience pleasure and pain, then non-human animals have interests. - T

2b. Non-human animals can experience pleasure and pain. - T

3b. Therefore, non-human animals have interests. - T

4b. If non-human animals have interests, then non-human animals are welfare subjects. - ?

5b. Therefore, non-human animals are welfare subjects. - ?

6b. If non-human animals are welfare subjects, then non-human animals are due moral consideration. - T

7b. Therefore, non-human animals are due moral consideration. - ?

Again, the implausible claim that non-human animals can't feel pleasure and pain is avoided, and the conditional in $6 \mathrm{~b}$ is affirmed. But if one rejects that welfare is a unitary concept, the fact that interest-satisfaction is constitutive of human welfare doesn't tell you anything about non-human animal welfare. By denying the unity of welfare, it is an open question whether "welfare" means the same thing for both humans and non-human animals. If one rejects the 
unity of welfare, one must be prepared to defend a separate account of the good-for relation for each type of welfare subject. It might even turn out that interest-satisfaction is constitutive of welfare for both humans and non-human animals. The point is just that one cannot infer this from the fact that interest-satisfaction is a constituent of human welfare unless one maintains that welfare is a unitary concept. If welfare is not unitary, the soundness of the first argument leaves premise $4 \mathrm{~b}$, and thus $5 \mathrm{~b}$ and $7 \mathrm{~b}$, with indeterminate truth-values. It is not inconsistent to accept the first argument but fail to affirm the conclusion of the second in this case, because whether this conclusion is true or false depends on what account of non-human animal welfare turns out to be true. Without the requirement that welfare is a unitary concept, this question remains open.

One might think that the generality requirement resolves this concern. After all, the generality requirement says that a theory of welfare must capture the core class of welfare subjects within its scope, and surely humans and most non-human animals fall equally into this category. But the generality requirement does not entail the unity of welfare. One might hold an interest-satisfaction theory of welfare for humans and a natural-living-based theory of welfare for non-human animals, with additional accounts of welfare included as needed to capture the core class of welfare subjects. One's theory of welfare would then effectively be a disjunction of several distinct, subject-specific accounts of the good-for relation. The generality of welfare requires only that one's theory of welfare capture the core class of welfare subjects; it does not require that one posit a single good-for relation in order to accomplish this task. Even if one accepts an interest-satisfaction theory of welfare for humans, along with the generality requirement, if one rejects that welfare is unitary, there is no inconsistency in affirming the moral considerability of humans while failing to grant equal moral consideration to nonhuman animals. One can simply remain agnostic about whether nonhuman animals are morally considerable, and one's theoretical 
commitments about welfare explain why such agnosticism is appropriate.

\section{Conclusion}

Sumner's proposed constraints on a theory of welfare are significant because they make our ordinary linguistic practices a kind of litmus test for the theoretical accuracy of proposed accounts of well -being. There is ample reason to welcome this proposal. Human well -being concerns how our lives are going for us, from our own point of view, and one might think that what we have to say about the matter is therefore highly relevant. Sumner's constraints also capture some of our more compelling intuitions about welfare: that the good-for relation is one type of relation, and that things can be genuinely good for a wide range of distinct types of subjects. Sumner's proposed constraints have the attractive features of linguistic compatibility and intuitive plausibility.

This paper has sought to show that there are other reasons to think Sumner's proposed constraints on a theory of welfare are significant, and worth further attention. Utilitarian arguments like that of Peter Singer continue to be some of the more compelling arguments for the equal moral considerability of non-human animals. These arguments unquestionably rely on both the generality and formality requirements for their success. If one rejects the generality of welfare, one can avoid the alleged inconsistency of denying the moral considerability of non-human animals while affirming it for humans by simply adopting a theory of welfare that does not capture non-human animals within its scope. If one rejects that welfare is unitary, one can accept Singer's argument that the moral considerability of humans ultimately depends on the fact that they have interests that can be satisfied or thwarted, but remain agnostic about whether non-human animals are morally considerable. This also avoids the alleged inconsistency. Utilitarian arguments for the moral considerability of non-human animals are thus importantly dependent on the unity of welfare and the generality requirement. If utilitarian arguments of this sort are to have a future, 
these constraints on a theory of welfare must be given more support than they have received thus far.

In closing, none of what has been said here demonstrates that utilitarian arguments like Singer's cannot succeed. It might be that welfare is a unitary concept, and that the generality requirement is a perfectly reasonable constraint on one's theory of welfare. But such constraints are not vindicated by their intuitive plausibility or their theoretical usefulness. Questions about the unity and generality of welfare thus remain significant areas for further research on welfare in general, and animal welfare in particular.

\section{References}

Frey, R.G. 1985. Rights, killing, and suffering. Oxford: Blackwell Publishing.

Frey, R.G. and Christopher Morris. 1993. Value, welfare, and morality. In Value, welfare, and morality, ed. R.G. Frey and Christopher Morris, 1-12. Cambridge: Cambridge University Press.

Rollin, Bernard E. 2006. Animal rights and human morality. Amherst: Prometheus Books.

Rosati, Connie S. 2009. Relational good and the multiplicity problem. Philosophical Issues 19:205-234.

Singer, Peter. 1975. Animal liberation. New York: Avon Books.

Sumner, L.W. 1996. Welfare, happiness, and ethics. Oxford: Clarendon Press.

Sumner, L.W. 1993. Welfare, preference, and rationality. In Value, welfare, and morality, ed. R.G. Frey and Christopher Morris, 74-92. Cambridge: Cambridge University Press.

Sumner, L.W. 2000. Something in between. In Well-being and morality, ed. Roger Crisp and Brad Hooker, 1-20. Oxford: Oxford University Press. 